\title{
Experimental Psychiatry
}

National Cancer Institute

\section{Source}

National Cancer Institute. Experimental Psychiatry. NCI Thesaurus. Code C17031.

A subdiscipline of psychiatry that is concerned with the study of conditioning, learning, perception, motivation, emotion, language, and thinking; also used in relation to subjectmatter areas in which experimental methods are emphasized. 